\title{
Enhancing the degradation efficiency of OPs under visible light by an integrated cascade photo-biocatalyst
}

\author{
Ying Zhang ${ }^{1}$, Xue Cao ${ }^{1}$, Xiaotian Wang ${ }^{1}$, Lihui Wang ${ }^{1}$, Sumin Guan ${ }^{1}$, Heyu $\mathrm{Li}^{2}$, Xiaobing \\ Zheng $^{1}$, Yanjun Jiang ${ }^{1}$, and Jing Gao ${ }^{1}$ \\ ${ }^{1}$ Hebei University of Technology \\ ${ }^{2}$ Tianjin UBasio Biotechnology Group Co., LTD.
}

September 28, 2020

\begin{abstract}
Photo-enzymatic integrated nanocatalyst which combined biocompatible photocatalytic carrier and OPH is designed to remove OPs. H-TiO2 microsphere is prepared using wrinkled $\mathrm{SiO} 2$ as template. Then, Au nanoparticles are loaded on the H-TiO2 to obtain $\mathrm{Au}-\mathrm{H}-\mathrm{TiO} 2$ heterojunction microsphere, which achieved effective use of visible light based on the SPR. The characterization results of $\mathrm{Au}-\mathrm{H}-\mathrm{TiO} 2$ prove that the $\mathrm{Au}-\mathrm{H}-\mathrm{TiO} 2$ has large specific surface area $(226.19 \mathrm{~m} 2 / \mathrm{g})$ and narrow band gap $(2.68$ eV). Adsorption methods are used to prepare OPH@Au-H-TiO2 by immobilizing OPH molecules. The obtained OPH@Au-H$\mathrm{TiO} 2$ can degrade methyl parathion to p-NP by OPH. Then the p-NP is degraded to hydroquinone with low toxicity using $\mathrm{Au}-\mathrm{H}-\mathrm{TiO} 2$. After $2.5 \mathrm{~h}$, methyl parathion is completely degraded, and about $82.64 \%$ of the generated p-NP is further degraded into hydroquinone. The fabricated OPH@Au-H-TiO2 has excellent catalytic activity and cycle stability, which is ascribed to the photo-enzyme synergic catalytic effect.
\end{abstract}

\section{Hosted file}

manuscript.pdf available at https://authorea.com/users/362249/articles/483734-enhancingthe-degradation-efficiency-of-ops-under-visible-light-by-an-integrated-cascade-photobiocatalyst 